\title{
A formalization of one of the main claims of "TDP-43 represses cryptic exon inclusion in FTD/ALS gene UNC13A" by Rosa Ma et al. $2021^{1}$
}

\author{
Matthew Brauer \\ Maze Therapeutics, USA \\ E-mail:mbrauer@mazetx.com; ORCID: https://orcid.org/0000-0003-2310-3013 \\ Editor: Cristina-Iulia Bucur (https://orcid.org/0000-0002-7114-6459) \\ Review comments from: Tobias Kuhn (https://orcid.org/0000-0002-1267-0234); Cristina-Iulia Bucur \\ (https://orcid.org/0000-0002-7114-6459)
}

Received 24 May 2021

Accepted 17 November 2021

Abstract. Rosa Ma et al. claimed in previous work that the protein TDP-43 represses cryptic exon inclusion in the gene UNC13A. We present here a formalization of that claim, stating that all things of class "TAR DNA binding protein" that are in the context of a thing of class "UNC13A" generally have a relation of type "inhibits" to a thing of class "inclusion of cryptic exon" in the same context.

Keywords: UNC13A, TAR DNA binding protein, inclusion of cryptic exon

\section{Introduction}

Rosa Ma et al. [2] state that "Here we show that TDP-43 represses a cryptic exon splicing event in UNC13A.". We present here a formalization of the main scientific claim from this quote by using a semantic template called the super-pattern [1].

\section{Formalization}

Our formalization looks as follows:

\footnotetext{
${ }^{1}$ As RDF/nanopublication: http://purl.org/np/RAXkuXJ4IK10Ai9F39_tOFDy6ewi7znau6OQhUEXP4nPc 


CONTEXT-CLASS ("in the context of all...”):
SUBJECT-CLASS ("things of type...”):
QUALIFIER:
RELATION-TYPE ("have a relation of type..."):
OBJECT-CLASS (“to things of type..."):

CONTEXT-CLASS (“in the context of all..."):

UNC13A

TAR DNA binding protein generally

inhibits

inclusion of cryptic exon

In the context class we use the "UNC13A" (Q18036664) class from Wikipedia. In subject class, we use the "TAR DNA binding protein" (Q21133247) from Wikidata. In the object class we used the "inclusion of cryptic exon" (VariO_0504) class from OBO ontology.

\section{RDF code}

This is our formalization as a nanopublication in TriG format:

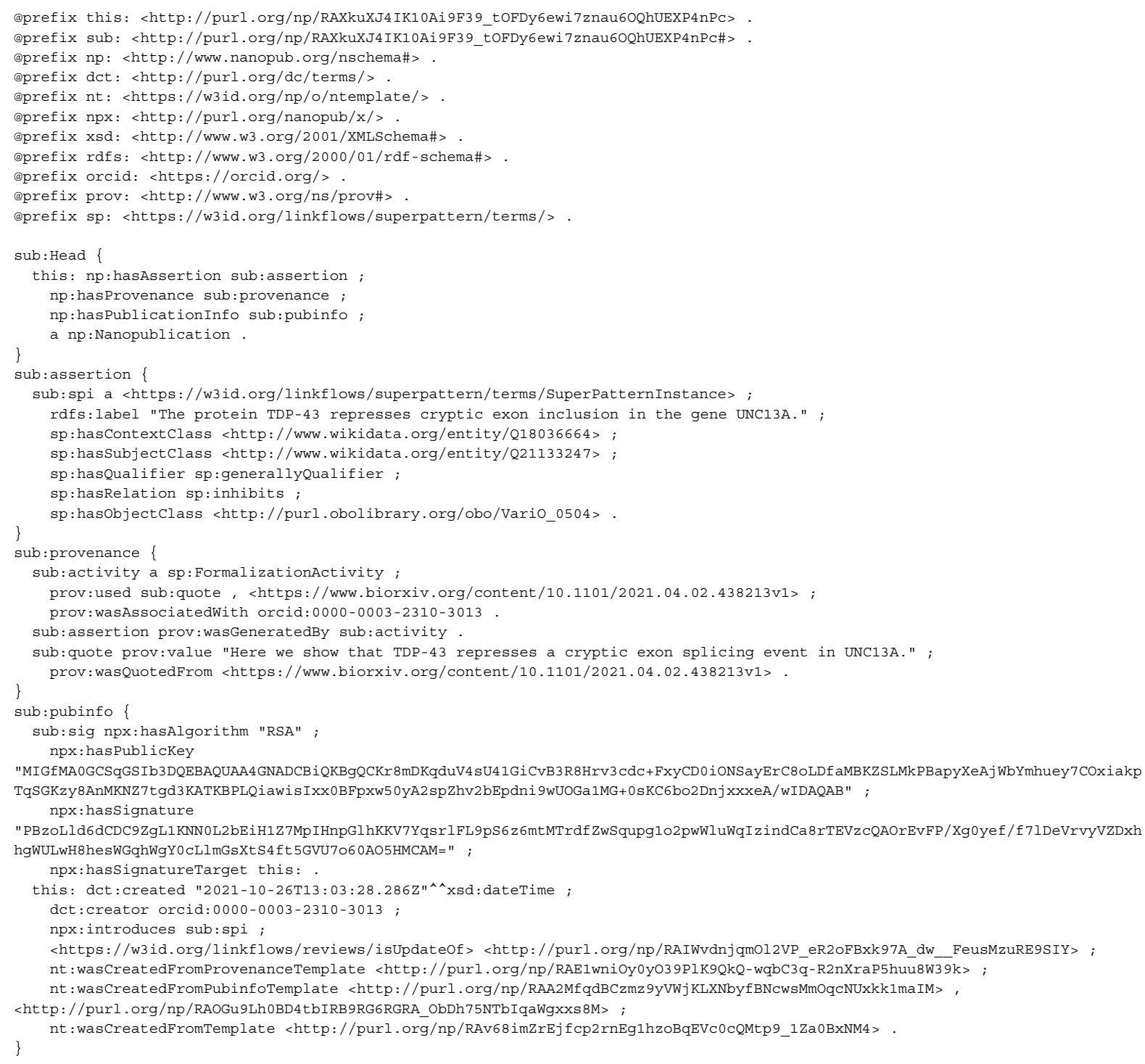




\section{References}

[1] C.I. Bucur, T. Kuhn, D. Ceolin and J. van Ossenbruggen, Expressing high-level scientific claims with formal semantics, in: Proceedings of the 11th Knowledge Capture Conference, 2021. doi:10.1145/3460210.3493561.

[2] X. Rosa Ma, M. Prudencio, Y. Koike, S.C. Vatsavayai, G. Kim, F. Harbinski, C.M. Rodriguez, H.B. Schmidt, B.B. Cummings, D.W. Wyatt, K. Kurylo, G. Miller, S. Mekhoubad, N. Sallee, K. Jansen-West, C.N. Cook, S. Pickles, B. Oskarsson, N.R. Graff-Radford, B.F. Boeve, D.S. Knopman, R.C. Petersen, D.W. Dickson, E.M. Green, W.W. Seeley, L. Petrucelli and A.D. Gitler, TDP-43 represses cryptic exon inclusion in FTD/ALS gene UNC13A, biorxiv. doi:10.1101/2021.04.02. 438213. 